\title{
KEMAMPUAN BERPIKIR KRITIS MAHASISWA MANAJEMEN UMSIDA DALAM MEMECAHKAN MASALAH MATEMATIKA BISNIS
}

\author{
Bayu Hari Prasojo ${ }^{1}$, Novia Ariyanti ${ }^{2}$ \\ ${ }^{1}$ Program Studi Manajemen, Fakultas Ekonomi Bisnis, Universitas Muhammadiyah Sidoarjo \\ ${ }^{2}$ Program Studi Teknik Informatika, Fakultas Teknik, Universitas Muhammadiyah Sidoarjo \\ jokosusilo1@umsida.ac.id ${ }^{1}$
}

\begin{abstract}
This descriptive study used a quantitative approach that aims at describing the students' critical thinking in solving business mathematics problems with respect to the origin of the school majors. Subjects were students of FEB management UMSIDA first half of the academic year 2016/2017. Data collection techniques in the form of tests to complete the Problem Solving Test (TPM) and the provision of critical thinking questionnaire relating to the work of students on TPM has been given. Data were analyzed using the average, percentage and Pearson Product Moment Correlation test (PPM). And the results showed that (1) the ability to solve business mathematics problems, student majoring in science studies is higher than the ability to solve mathematical problems business student majoring in social studies or student majoring in vocational school (2) critical thinking skills of students majoring in science studies, social studies and vocational school overall thinking ability critical successively shows the critical criterion, quite critical and critical enough (3) critical thinking skills of students at every step of Polya's Problem Solving as follows: (a) at the stage Understanding the problem, a student of the science studies showed criteria please critical, a student of the social studies indicate criteria quite Critical and student of vocational school indicate the criteria fairly Critical $(b)$ at the stage Make a Plan, a student of the science studies indicates the criteria fairly critical, a student of the social studies indicate criteria is quite critical and student of vocational school indicate the criteria fairly Critical $(c)$ at the stage implement the plan, a student of the science studies showed criteria please Critical, a student of the social studies indicate criteria please Critical and student of vocational school indicate criteria please Critical (c) at the stage Checking Back, a student of the science studies indicates the criteria Critical, a student of the social studies show Critical criteria and student of vocational schools show the criteria, please Critical (4) there is a strong relationship between Business Mathematics problem Solving ability with Students Critical Thinking Skills.
\end{abstract}

Keywords: evaluation of learning, realibility, discrimination power

\section{PENDAHULUAN}

Kemampuan berpikir kritis sangat penting dimiliki oleh setiap individu karena dengan berpikir kritis seseorang akan lebih bijak dalam menghadapi segala kejadian dalam kehidupannya. Tujuan dari berpikir kritis adalah untuk mencapai pemahaman yang mendalam (Johnson, 2007: 185). Dengan pemahaman yang mendalam tersebut seseorang akan mampu mengungkap makna dibalik informasi yang diperoleh sehingga dapat menemukan kebenaran di tengah banyaknya informasi yang tersedia, berguna bagi pengambilan keputusan dan menyelesaikan masalah. Untuk menilai berpikir kritis seseorang, Ennis (1996: 4- 8) memperkenalkan enam kriteria berpikir kritis FRISCO (Focus, Reason, Inference, Situation, Clarity Overview).

Dengan demikian, kemampuan berpikir kritis perlu dimiliki oleh mahasiswa dalam mendukung ketepatan dalam pengambilan keputusan dan menyelesaikan masalah. Hal ini sesuai dengan tujuan program studi manajemen UMSIDA yang menyiapkan mahasiswa untuk dapat mengembangkan diri secara maksimal, menjadi calon manajer atau wirausahawan yang berintegritas, berintelektual dan memiliki kemampuan komunikasi, analisis, pengambilan keputusan dan penyelesaian permasalahan, penggunaan teknologi informasi komunikasi, dan team work dalam bidang bisnis dan organisasi baik di pasar domestik maupun global dengan berlandaskan pada nilai-nilai moral yang Islami, etika dan profesional untuk melayani masyarakat.

Profil berpikir kritis mahasiswa dapat dilihat dari aktivitas mahasiswa dalam memecahkan masalah. Dimana profil tersebut akan menggambarkan tentang aktivitas mental yang memenuhi kriteria FRISCO (Focus, Reason, Inference, Situation, Clarity Overview) pada setiap langkah pemecahan Polya. Hal ini sesuai dengan pendapat yang dikemukakan oleh Sabandar (2009) dan Johnson 
(2007) bahwa ada hubungan antara berpikir kritis siswa dengan kemampuan pemecahan masalah.

Hasil penelitian ini akan menghasilkan luaran berupa profil mengenai berpikir kritis mahasiswa dalam menyelesaikan masalah matematika bisnis ditinjau dari jurusan sekolah yang nantinya akan digunakan sebagai acuan untuk mengupayakan bagaimana strategi yang dapat digunakan dalam proses pembelajaran agar mahasiswa dapat mencapai tingkat berpikir kritis yang lebih tinggi. Pemilihan asal jurusan sebagai acuan subjek penelitian didasarkan pada heterogenitas asal jurusan mahasiswa FEB.

\section{METODE}

Subyek penelitian ini adalah mahasiswa dengan latar belakang jurusan sekolah yang berbeda yaitu jurusan IPA, IPS dan SMK dikarenakan di prodi ini latar belakang jurusan sekolahnya heterogen. Namun, tidak semua mahasiswa yang akan diteliti. Subyek penelitian ini adalah 16 orang mahasiswa yang masing-masing mewakili jurusan IPA, IPS dan SMK Prodi Manajemen FEB UMSIDA. Teknik pengambilan sampel subyek penelitian ini menggunakan Stratified Random/Sampling yaitu dengan cara pengelompokkan mahasiswa berdasarkan kategori asal jurusan sekolah yaitu IPA, IPS dan SMK dimana masing-masing kategori diambil 16 mahasiswa secara acak.

Teknik pengumpulan data penelitian meliputi pengumpulan data profil berpikir kritis dalam memecahkan masalah dilakukan dengan tes tertulis. Subjek diminta mengerjakan TPM yang berupa satu masalah matematika bisnis. Hasil TPM selanjutnya ditelaah oleh peneliti dan kemudian ditindak lanjuti dengan kuisioner berpikir kritis untuk melengkapi data yang belum terkumpul.

Dalam penelitian ini pemberian kuisioner berpikir kritis dilakukan untuk mengklarifikasi jawaban mahasiswa terhadap TPM yang telah diberikan dan untuk menggali data yang tidak dapat diidentifikasi dari hasil tertulis TPM. Dengan kuisioner ini peneliti dapat mengetahui kinerja mahasiswa untuk menilai kriteria berpikir kritis FRISCO yang dilakukan mahasiswa sehingga memperjelas data yang diperoleh agar dapat ditarik kesimpulan.

Dari proses yang telah dilakukan tersebut kemudian dilakukan analisis terhadap data yang telah diperoleh meliputi : Analisis hasil TPM diperoleh dari Tes yang diberikan kepada subyek penelitian berupa soal essay yang berisi satu masalah matematika bisnis. Penilaian hasil TPM berdasarkan pedoman penilaian yang telah dibuat dengan penskoran 0 sampai 100. Setelah masingmasing subyek diberikan skor, kemudian dihitung nilai rata-rata dari masing-masing jurusan sekolah (IPA, IPS dan SMK), setelah itu dilakukan perbandingan dan analisis untuk mendapatkan deskripsi TPM. Analisis data berpikir kritis meliputi enam indikator berpikir kritis FRISCO pada setiap langkah pemecahan masalah Polya. Dari enam indikator berpikir kritis FRISCO pada setiap langkah pemecahan masalah Polya tersebut, kemudian dibuat kuisioner berjumlah 24 pernyataan dengan menggunakan 4 skala Liekert. Analisis data berpikir kritis dihitung dengan menggunakan langkah-langkah sebagai berikut (1995):

1. Menghitung kuisioner yang telah diberikan kepada mahasiswa pada saat selesai mengerjakan TPM menggunakan pedoman penskoran yang telah dibuat. Kemudian memasukkan data hasil kuisioner tersebut sesuai dengan jurusan sekolah di Microsoft excel;

2. Menghitung persentase skor berpikir kritis setiap mahasiswa pada setiap jurusan sekolah;

3. Menghitung persentase skor berpikir kritis seluruh mahasiswa pada setiap jurusan sekolah;

4. Menghitung persentase skor berpikir kritis pada setiap langkah pemecahan Polya pada setiap jurusan;

5. Menentukan kriteria berpikir kritis berdasarkan PAP menurut Masidja.

Tabel 1. Penilaian Acuan Patokan (PAP)

\begin{tabular}{|cc}
\hline Rentang Persentase & Keterangan \\
$90 \%-100 \%$ & Sangat Kritis \\
$80 \%-89 \%$ & Kritis \\
$65 \%-79 \%$ & Cukup Kritis \\
$55 \%-64 \%$ & Tidak Kritis \\
Dibawah $55 \%$ & Sangat Tidak Kritis \\
\hline \hline
\end{tabular}


Analisis Hubungan antara Kemampuan Matematika Bisnis dengan Berpikir Kritisdigunakan untuk mengetahui hubungan antara kemampuan matematika bisnis dengan berpikir kritis mahasiswa digunakan analisis Korelasi Pearson Product Moment (PPM), kemudian untuk mengetahui tingkat hubungannya maka nilai $r$ koefisien korelasi PPM yang diperoleh dari analisis menggunakan SPSS 20 diinterpretasikan sesuai dengan interpretasi koefisien korelasi sebagai berikut (Setyowati, 2011):

Tabel 2. Interpretasi Koefisien Korelasi Nilai $r$

Interval Koefisien Korelasi $r$
$0,80-1,00$
$0,60-0,79$
$0,40-0,59$
$0,20-0,39$
$0,00-0,19$

\section{Interpretasi}

Sangat Kuat Kuat

Cukup Kuat

Rendah

Sangat Rendah

\section{HASIL DAN PEMBAHASAN}

Pada kemampuan memecahkan masalah matematika bisnis berdasarkan data pada tabel 3. hasil TPM menunjukkan bahwa nilai rata-rata mahasiswa jurusan sekolah IPA memiliki nilai rata-rata tertinggi yaitu 72,63 dibandingkan nilai rata-rata mahasiswa jurusan sekolah IPS dan SMK masing-masing yaitu 62,19 dan 60,50. Hal ini menunjukkan mahasiswa jurusan sekolah IPA mempunyai kemampuan menyelesaikan masalah matematika bisnis yang lebih baik dari pada mahasiswa jurusan sekolah IPS dan SMK. Sementara itu, untuk nilai standar deviasi mahasiswa jurusan sekolah IPA lebih kecil yaitu 24,82 dari pada nilai standar deviasi mahasiswa jurusan sekolah SMK dan IPS yaitu masingmasing 31,43 dan 32,17. Hal ini menunjukkan bahwa nilai mahasiswa jurusan sekolah IPA lebih relatif sama dibandingkan nilai mahasiswa jurusan sekolah SMK dan IPS dengan kata lain kemampuan menyelesaikan masalah matematika bisnis mahasiswa jurusan sekolah IPA relatif sama jika dibandingkan dengan mahasiswa jurusan sekolah SMK dan IPS.

Tabel 3. Hasil TPM Mahasiswa Berdasarkan Jurusan Sekolah

\begin{tabular}{|c|c|c|c|c|}
\hline No & Uraian & IPA & IPS & SMK \\
\hline 1 & Nilai Rata-rata & 2,63 & 2,19 & 0,50 \\
\hline 2 & Nilai Tertinggi & 100 & 100 & 100 \\
\hline 3 & Nilai Terendah & 26 & 6 & 18 \\
\hline 4 & Simpangan Baku & 24,82 & 32,17 & 31,43 \\
\hline
\end{tabular}

Berdasarkan Tabel 4 kemampuan berpikir kritis mahasiswa jurusan sekolah IPA memiliki rata-rata skor 75,9 dengan kriteria "Kritis" dimana terdapat 15 mahasiswa yang termasuk dalam kriteria minimal cukup kritis dengan persentase 94\% mahasiswa yang memiliki kemampuan berpikir kritis. Kemampuan berpikir kritis mahasiswa jurusan sekolah IPS memiliki rata-rata skor 72,9 dengan kriteria "Cukup Kritis" dimana terdapat 12 mahasiswa yang termasuk dalam kriteria minimal cukup kritis dengan persentase $75 \%$ mahasiswa yang memiliki kemampuan berpikir kritis. Dan kemampuan berpikir kritis mahasiswa jurusan sekolah SMK memiliki rata-rata skor 69,2 dengan kriteria "Cukup Kritis" dimana terdapat 13 mahasiswa yang termasuk dalam kriteria minimal cukup kritis dengan persentase $81 \%$ mahasiswa yang memiliki kemampuan berpikir kritis.

Tabel 4. Data Berpikir Kritis Mahasiswa Asal Jurusan Sekolah

\begin{tabular}{|c|c|c|c|c|c|c|c|c|c|c|c|c|}
\hline No & Jurusan & Skor & $\%$ & Kriteria & Jurusan & Skor & $\%$ & Kriteria & Jurusan & Skor & $\%$ & Kriteria \\
\hline 1 & \multirow{4}{*}{ IPA } & 90 & 93.8 & $\begin{array}{l}\text { Sangat } \\
\text { Kritis }\end{array}$ & \multirow{4}{*}{ IPS } & 59 & 61.5 & $\begin{array}{l}\text { Tidak } \\
\text { Kritis }\end{array}$ & \multirow{4}{*}{ SMK } & 63 & 65.6 & $\begin{array}{c}\text { Cukup } \\
\text { Kritis }\end{array}$ \\
\hline 2 & & 69 & 71.9 & $\begin{array}{l}\text { Cukup } \\
\text { Kritis }\end{array}$ & & 73 & 76.0 & $\begin{array}{l}\text { Cukup } \\
\text { Kritis }\end{array}$ & & 67 & 69.8 & $\begin{array}{l}\text { Cukup } \\
\text { Kritis }\end{array}$ \\
\hline 3 & & 78 & 81.3 & Kritis & & 81 & 84.4 & Kritis & & 65 & 67.7 & $\begin{array}{l}\text { Cukup } \\
\text { Kritis }\end{array}$ \\
\hline 4 & & 68 & 70.8 & $\begin{array}{l}\text { Cukup } \\
\text { Kritis }\end{array}$ & & 60 & 62.5 & $\begin{array}{l}\text { Tidak } \\
\text { Kritis }\end{array}$ & & 71 & 74.0 & $\begin{array}{l}\text { Cukup } \\
\text { Kritis }\end{array}$ \\
\hline
\end{tabular}




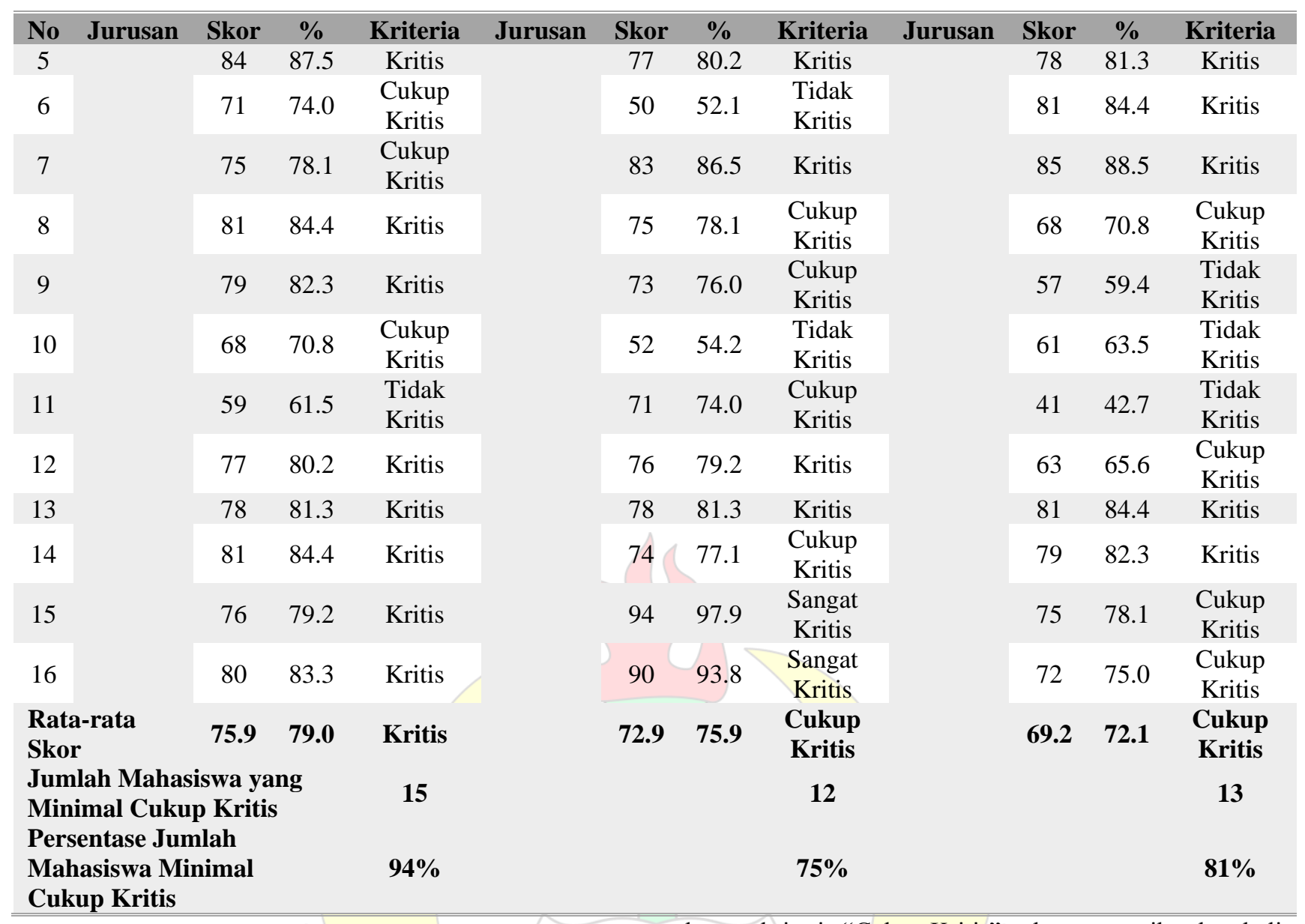

Hal tersebut menunjukkan bahwa kriteria berpikir kritis mahasiswa jurusan sekolah IPA lebih tinggi daripada mahasiswa jurusan sekolah IPS dan SMK, akan tetapi secara keseluruhan kriteria berpikir kritis mahasiswa dari ketiga jurusan sekolah tersebut sudah berada pada kriteria minimal "Cukup Kritis".

Sementara itu berdasarkan Tabel 5., kemampuan berpikir kritis mahasiswa pada setiap langkah pemecahan Polya menunjukkan bahwa mahasiswa jurusan sekolah IPA pada tahap memahami masalah memiliki rata-rata skor 3,15 dengan kriteria "Cukup Kritis", tahap membuat rencana memiliki rata-rata skor 3,05 dengan kriteria "Cukup Kritis", tahap melaksanakan rencana memiliki rata-rata skor 2,99 dengan kriteria "Cukup Kritis", tahap memeriksa kembali memiliki rata-rata skor 3,46 dengan kriteria "Kritis" dan secara keseluruhan memiliki ratarata skor 3,16 dengan kriteria "Kritis".

Mahasiswa jurusan sekolah IPS pada tahap memahami masalah memiliki rata-rata skor 2,95 dengan kriteria "Cukup Kritis", tahap membuat rencana memiliki rata-rata skor 2,95 dengan kriteria "Cukup Kritis", tahap melaksanakan rencana memiliki rata-rata skor 2,99 dengan kriteria "Cukup Kritis", tahap memeriksa kembali memiliki rata-rata skor 3,26 dengan kriteria "Kritis" dan secara keseluruhan memiliki rata-rata skor 3,04 dengan kriteria "Cukup Kritis".

Mahasiswa jurusan sekolah SMK pada tahap memahami masalah memiliki rata-rata skor 2,97 dengan kriteria "Cukup Kritis", tahap membuat rencana memiliki rata-rata skor 2,73 dengan kriteria "Cukup Kritis", tahap melaksanakan rencana memiliki rata-rata skor 2,77 dengan kriteria "Cukup Kritis", tahap memeriksa kembali memiliki rata-rata skor 3,06 dengan kriteria "Cukup Kritis" dan secara keseluruhan memiliki rata-rata skor 2,88 dengan kriteria "Cukup Kritis". 
Tabel 5. Data Berpikir Kritis Mahasiswa pada Setiap Langkah Pemecahan Polya

\begin{tabular}{|c|c|c|c|c|c|c|c|}
\hline \multirow[t]{2}{*}{ No } & \multirow[t]{2}{*}{ Langkah Pemecahan Polya } & \multicolumn{2}{|c|}{ Jurusan Sekolah } & \multirow[b]{2}{*}{ IPS } & \multirow[b]{2}{*}{ Kriteria } & \multirow[b]{2}{*}{ SMK } & \multirow[b]{2}{*}{ Kriteria } \\
\hline & & IPA & Kriteria & & & & \\
\hline 1 & Memahami Masalah & 3,15 & Cukup Kritis & 2,95 & Cukup Kritis & 2,97 & Cukup Kritis \\
\hline 2 & Membuat Rencana & 3,05 & Cukup Kritis & 2,95 & Cukup Kritis & 2,73 & Cukup Kritis \\
\hline 3 & Melaksanakan Rencana & 2,99 & Cukup Kritis & 2,99 & Cukup Kritis & 2,77 & Cukup Kritis \\
\hline 4 & Memeriksa Kembali & 3,46 & Kritis & 3,26 & Kritis & 3,06 & Cukup Kritis \\
\hline & Rata-rata Skor Total & 3,16 & Kritis & 3,04 & Cukup Kritis & 2,88 & Cukup Kritis \\
\hline
\end{tabular}

Berdasarkan Tabel 6 hasil uji Korelasi Pearson Product Moment (PPM) dapat diketahui bahwa untuk mahasiswa jurusan sekolah IPA Sig (2-tailed) $0,000<$ 0,05 sehingga dapat disimpulkan bahwa terdapat hubungan antara kemampuan memecahkan masalah matematika bisnis dengan berpikir kritis mahasiswa. Selain itu diketahui pula nilai Korelasi Pearson 0,910 maka berdasarkan tabel 3.2. maka tingkat hubungan antara kemampuan memecahkan masalah matematika bisnis dengan berpikir kritis mahasiswa sangat kuat.

Tabel 6. Korelasi Kemampuan Matematika Bisnis dan Berpikir Kritis Mahasiswa Jurusan Sekolah IPA

\begin{tabular}{|cc|c|r|}
\hline \multicolumn{2}{c|}{ Correlations } & \multicolumn{2}{c|}{ Kemampuan } \\
Merpikir Kritis \\
\hline
\end{tabular}

**. Correlation is significant at the 0.01 level (2-tailed).

Hasil uji Korelasi Pearson Product Moment (PPM) pada Tabel 7 dapat diketahui bahwa untuk mahasiswa jurusan sekolah IPS Sig (2-tailed) 0,000 <0,05 sehingga dapat disimpulkan bahwa terdapat hubungan antara kemampuan memecahkan masalah matematika bisnis dengan berpikir kritis mahasiswa. Selain itu diketahui pula nilai Korelasi Pearson 0,928 maka berdasarkan
Tabel 3 dan Tabel 2 maka tingkat hubungan antara kemampuan memecahkan masalah matematika bisnis dengan berpikir kritis mahasiswa sangat kuat.

Tabel 7. Korelasi Kemampuan Matematika Bisnis dan Berpikir Kritis Mahasiswa Jurusan Sekolah IPS

\section{Correlations}

\begin{tabular}{|cc|c|r|}
\hline & & Kemampuan & \multicolumn{2}{c|}{ Berpikir Kritis } \\
\hline & & Matematika Bisnis & \\
Kemampuan Matematika Bisnis & Pearson Correlation & 1 & $.928^{* *}$ \\
& Sig. (2-tailed) & .000 \\
Berpikir Kritis & $\mathrm{N}$ & $.928^{* *}$ & .000 \\
& Pearson Correlation & 16 & 1 \\
& Sig. (2-tailed) & $\mathrm{N}$ & 16 \\
\hline
\end{tabular}

\footnotetext{
**. Correlation is significant at the 0.01 level (2-tailed).
} 
Hasil uji Korelasi Pearson Product Moment (PPM) pada Tabel 8 dapat diketahui bahwa untuk mahasiswa jurusan sekolah SMK Sig (2-tailed) $0,000<0,05$ sehingga dapat disimpulkan bahwa terdapat hubungan antara kemampuan memecahkan masalah matematika bisnis dengan berpikir kritis mahasiswa. Selain itu diketahui pula nilai Korelasi Pearson 0,845 maka berdasarkan Tabel 3 dan Tabel 2 maka tingkat hubungan antara kemampuan memecahkan masalah matematika bisnis dengan berpikir kritis mahasiswa sangat kuat.

Tabel 8. Korelasi Kemampuan Matematika Bisnis dan Berpikir Kritis Mahasiswa Jurusan Sekolah SMK

\section{Correlations}

\begin{tabular}{|cc|c|r|}
\hline & & Kemampuan & \multicolumn{2}{c|}{ Berpikir Kritis } \\
\hline & & Matematika Bisnis & $.845^{* *}$ \\
Kemampuan Matematika Bisnis & Pearson Correlation & 1 & .000 \\
& Sig. (2-tailed) & 16 & 16 \\
& $\mathrm{~N}$ & $.845^{* *}$ & .000 \\
Berpikir Kritis & Pearson Correlation & 16 & 1 \\
& Sig. (2-tailed) & $\mathrm{N}$ & 16 \\
\hline
\end{tabular}

**. Correlation is significant at the 0.01 level (2-tailed).

Berdasarkan hasil diatas maka hal ini menunjukkan bahwa jika kemampuan memecahkan masalah matematika bisnis tinggi maka tingkat berpikir kritis mahasiswa juga tinggi. Sebaliknya, jika kemampuan

\section{PENUTUP}

\section{Simpulan}

Berdasarkan penelitian yang telah dilakukan dapat diambil beberapa simpulan sebagai berikut : (1) Kemampuan memecahkan masalah matematika bisnis mahasiswa jurusan sekolah IPA lebih tinggi daripada kemampuan memecahkan masalah matematika bisnis mahasiswa jurusan sekolah IPS dan jurusan sekolah SMK. (2) Kemampuan berpikir kritis mahasiswa jurusan sekolah IPA tersebar dalam empat kriteria yaitu tidak kritis, cukup kritis, kritis dan sangat kritis. Secara keseluruhan kemampuan berpikir kritisnya menunjukkan kriteria kritis. Sementara itu, kemampuan berpikir kritis mahasiswa jurusan sekolah IPS tersebar dalam empat kriteria yaitu tidak kritis, cukup kritis, kritis dan sangat kritis. Secara keseluruhan kemampuan berpikir kritisnya menunjukkan kriteria cukup kritis. Dan kemampuan berpikir kritis mahasiswa jurusan sekolah SMK tersebar dalam tiga kriteria yaitu tidak kritis, cukup kritis, dan kritis. Secara keseluruhan kemampuan berpikir kritisnya menunjukkan kriteria cukup kritis. (3) Kemampuan berpikir kritis mahasiswa pada setiap langkah pemecahan Polya sebagai berikut : (a) Pada tahap Memahami Masalah, mahasiswa jurusan sekolah IPA menunjukkan kriteria Cukup Kritis, mahasiswa jurusan sekolah IPS menunjukkan kriteria Cukup Kritis dan mahasiswa memecahkan masalah matematika bisnis rendah maka tingkat berpikir kritis mahasiswa juga rendah.

jurusan sekolah SMK menunjukkan kriteria Cukup Kritis. (b) Pada tahap Membuat Rencana, mahasiswa jurusan sekolah IPA menunjukkan kriteria Cukup Kritis, mahasiswa jurusan sekolah IPS menunjukkan kriteria Cukup Kritis dan mahasiswa jurusan sekolah SMK menunjukkan kriteria Cukup Kritis. (c) Pada tahap Melaksanakan Rencana, mahasiswa jurusan sekolah IPA menunjukkan kriteria Cukup Kritis, mahasiswa jurusan sekolah IPS menunjukkan kriteria Cukup Kritis dan mahasiswa jurusan sekolah SMK menunjukkan kriteria Cukup Kritis. (d) Pada tahap Memeriksa Kembali, mahasiswa jurusan sekolah IPA menunjukkan kriteria Kritis, mahasiswa jurusan sekolah IPS menunjukkan kriteria Kritis dan mahasiswa jurusan sekolah SMK menunjukkan kriteria Cukup Kritis. (4) Terdapat hubungan yang kuat antara Kemampuan Memecahkan Masalah Matematika Bisnis dengan Kemampuan Berpikir Kritis Mahasiswa.

\section{Saran}

Diharapkan adanya rentang waktu yang cukup agar penelitian dapat dilaksanakan dengan maksimal. Pemilihan subyek penelitian yang lebih representatif agar didapatkan hasil penelitian yang lebih baik. Diharapkan adanya penelitian lanjutan yang menggunakan pemecahan masalah matematika bisnis untuk membentuk 
kemampuan berpikir kritis atau kemampuan berpikir yang lainnya.

\section{DAFTAR PUSTAKA}

Duron, R, dkk. (2006).“Critical Thinking Framework for Any Discipline”. International Journal of Teaching and Learning in Higher Education. Vol. 17 : 160-166.

Ennis, Robert H. (1996). Critical Thinking. New Jersey : Printice-Hall Inc.

Filsaime, D.K. (2008). Menguak Rahasia Berpikir Kritis dan Kreatif. Jakarta: Prestasi Pustaka

Fisher, Alec. (2009). Berpikir Kritis. Sebuah Pengantar. Jakarta: Penerbit Erlangga.

Johnson, Elaine. (2009). Contextual Teaching and Learning. Bandung : Mizan Media Utama.

Masidja, I. (1995). Penilaian Pencapaian Hasil Belajar Siswa di Sekolah. Yogyakarta : Kanisius.

Miles dan Huberman. (2007). Analisis Data Kualitatif, Buku Sumber tentang Metode-metode Baru. Jakarta : Universitas Indonesia Press

Moleong, Lexy J. (2005). Metodologi Penelitian Kualitatif. Bandung : Remaja Rosdakarya

Polya, G. (1973). How to Solve It. New Jersey : Princenton University Press

Polya, G. (1981). Mathematical Discovery. New York : John Wiley \& Sons Inc.

Prastowo, Andi. (2010). Menguasai Teknik-teknik Koleksi Data Penelitian Kualitatif. Jogjakarta : DIVA Press

Rohmatin, Dian Novita. (2012). Profil Berpikir Kritis Siswa SMP dalam Memecahkan Masalah Geometri Ditinjau dari Tingkat IQ. Tesis pada PPS Unesa Surabaya : Tidak diterbitkan

Sabandar, Jozua. (2009). Berpikir Reflektif. [Online]. http://math.sps.upi.edu/?s=berpikir+reflektif. Diakses tanggal 2 September 2013.

Setyowati, A. 2011. Implementasi Pendekatan Konflik Kognitif dalam Pembelajaran Fisika untuk Menumbuhkan Kemampuan Berpikir Kritis Siswa Kelas VIII. Jurnal Pendidikan Fisika Indonesia. 7 : 89-96.

Siswono. T. Y. E. (2008). Berpikir Kreatif melalui Pemecahan dan Pengajuan Masalah. Surabaya : Unesa. 
Bayu Hari Prasojo ${ }^{1}$, Novia Ariyanti ${ }^{2}$ : Kemampuan Berpikir Kritis Mahasiswa Manajemen FEB UMSIDA Dalam Memecahkan Masalah Matematika Bisnis 